\title{
Reflexões sobre a prática docente o desafio da qualidade no PROEJA
}

\author{
Helen Wanderley do Prado ${ }^{1}$
}

Jupter Martins de Abreu Junior ${ }^{2}$

\begin{abstract}
Resumo
O PROEJA é um programa que visa a oferta da educação profissional integrada à educação básica na modalidade EJA, sendo oferecido, principalmente, em instituições federais, que têm o seu histórico marcado pelo discurso da excelência. Inserido neste contexto, este trabalho pretende, por meio de revisão bibliográfica e análise documental, refletir sobre a prática docente e o desafio da qualidade no PROEJA. O referencial teórico abarca autores que se dedicam à modalidade EJA e ao Programa, como Paiva, Machado, Ventura e Moll, entre outros. Constatou-se que há entraves que penetram no processo educativo e dificultam a construção de uma prática educativa emancipatória. Palavras-chave: Proeja; Prática Docente; Qualidade.
\end{abstract}

\section{Reflections on teaching practice the challenge of quality in PROEJA}

\section{Abstract}

The PROEJA is a program that aims to offer professional education integrated with basic education in the EJA modality, being offered mainly in federal institutions that have a history marked by the discourse of excellence. Inserted in this context, this work intends, through bibliographic review and document analysis, to reflect on the teaching practice and the challenge of quality in PROEJA. The theoretical framework includes authors who are dedicated to the EJA modality and the Program, such as Paiva, Machado, Ventura and Moll, among others. It was found that there are barriers that penetrate the educational process and hinder the construction of an emancipatory educational practice.

Keywords: Proeja; Teaching Practice; Quality.

\section{Introdução}

Em 1990, a Declaração Mundial sobre Educação para Todos reafirmou oficialmente o princípio de uma educação de qualidade como direito, ressaltando a importância da garantia do acesso e a permanência de todos na escola. Foram criadas políticas de correção de fluxo, o que contribuiu para a universalização do ensino fundamental. Houve uma expansão do sistema escolar, principalmente no ensino médio.

As políticas de correção de fluxo, de fato, contribuíram para a permanência dos jovens na

\footnotetext{
${ }^{1}$ Instituto Federal de Educação, Ciência e Tecnologia do Rio de Janeiro, Rio de Janeiro, helen.prado@ifrj.edu.br.

${ }^{2}$ Instituto Federal de Educação, Ciência e Tecnologia do Rio de Janeiro, Rio de Janeiro, jupter.junior@ifrj.edu.br.
} 
escola, mas não tiveram grandes impactos na questão do desempenho escolar. Assim, pode-se dizer que o sistema escolar se ampliou, mas manteve os sujeitos das classes desfavorecidas às "margens" do seu interior, gerando uma demanda potencial para a Educação de Jovens e Adultos. Além disso, a elevada distorção idade série no Brasil fez com que "o processo social de universalização de escolarização seja acompanhado pelo fracasso escolar" (ESTEBAN, 2013, p.23). Nesse sentido:

[...] à medida que o acesso ao sistema escolar se "democratiza", permitindo que os segmentos menos favorecidos da sociedade frequentem a escola, cresce o número daqueles que não conseguem responder adequadamente às exigências escolares, constituindo um problema em seu próprio interior (ESTEBAN, 2013, p.23).

A partir dos anos de 1990, o Brasil viveu um conjunto de reformas que marcaram as políticas educacionais. Como consequência, "no final da década de 1990 o atendimento à Educação de Jovens e Adultos (EJA) era descontínuo e diversificado". (VENTURA, 2011, p.81). Existiam muitas iniciativas fragmentadas e caracterizadas por formações aligeiradas, desvinculadas, muitas vezes, da formação para o trabalho.

Em meio a um cenário de pressões da sociedade civil e de setores da comunidade educacional pela superação do Decreto n.2.208/97, que separava a educação básica da formação profissional, foi promulgado o Decreto n.5.154/04, que restabeleceu a possibilidade da organização curricular integrada de educação profissional e educação geral, no âmbito do ensino médio (BRASIL, 1997, 2004).

Tal iniciativa viabilizou o Decreto n.5.478/2005, que regulamentou o Programa de Integração da Educação Técnica de Nível Médio na modalidade de Educação de Jovens e Adultos (PROEJA), instituído pelo governo federal, com o objetivo de atender à demanda de jovens e adultos pela oferta da educação profissional técnica de nível médio, da qual, no geral, são excluídos.

Posteriormente, em 2006, o Decreto no 5.478/2005, que criou o PROEJA, foi substituído pelo Decreto no 5.840/2006, que ampliou a abrangência do Programa para o público do ensino fundamental, passando a ser denominado Programa Nacional de Integração da Educação Profissional com a Educação Básica na Modalidade de Educação de Jovens e Adultos (PROEJA). 
O PROEJA pretende oficialmente resgatar o direito desses sujeitos de concluírem a educação básica e de terem acesso a uma formação profissional de qualidade. Desta forma, se difere das políticas implementadas na década de 1990, pois coloca em foco a perspectiva de uma educação integrada a partir de uma concepção humanística, que tem como objetivo a emancipação dos sujeitos. Nesse sentido, rompe com a perspectiva de formação fragmentada ainda presente nas políticas de EJA, que não tem a qualidade como premissa. Desta forma, a prática docente assume um papel fundamental de uma práxis emancipatória.

Inserido nesse contexto, o presente trabalho busca refletir sobre a prática docente e o desafio da qualidade no PROEJA, visto que a garantia do direito à educação ainda é um dos principais dilemas enfrentados pelo campo da EJA no Brasil, principalmente no cenário políticosocial contemporâneo.

Para atingir esses objetivos, foram utilizados como procedimentos metodológicos a revisão bibliográfica e análise documental acerca das temáticas abordadas. Embora possuam algumas diferenças, a pesquisa documental e a pesquisa bibliográfica podem ser utilizadas como procedimentos metodológicos complementares, com o intuito de criar novas formas de compreender os fenômenos e produzir novos conhecimentos.

A análise documental abrange Documentos Base do PROEJA (2006 e 2007) e os decretos (2.208/1997; 5.154/2004; 5.478/2005 e 5.840/2006) que, de certa forma, possuem relação com a implementação do Programa. A revisão bibliográfica se baseou em autores que se dedicam a EJA, como: Andrade (2004), Machado (2009), Ventura (2011), Paiva (2013), entre outros. Também contemplou autores que estudam o PROEJA, de modo geral, como: Moll (2010) e Machado (2011), assim como no âmbito das práticas pedagógicas e formação docente, como: Shiroma e Lima Filho (2011), Santos, Martins e Baracho (2010). Em relação ao conceito de qualidade, nos sustentamos no Documento Final CONAE (2010) e em autores como Esteban (2013) e Paiva (2013), que contribuem para o debate da qualidade na Educação de Jovens e Adultos.

Tomamos como referência o conceito de qualidade, numa perspectiva polissêmica, considerando que o termo compreende aspectos intra e extra escolares que tem relação com o processo educativo e com a garantia de acesso, permanência e êxito na escola. Nesse contexto, corroboramos com a concepção de que "a discussão acerca da qualidade da educação suscita 
definição do que se entende por educação" (BRASIL, 2010, p.46).

Numa visão ampla, ela é entendida como elemento partícipe das relações sociais, contribuindo, contraditoriamente, para a transformação e a manutenção dessas relações", (BRASIL, 2010, p.46), apresentando múltiplas dimensões e significações. Nesse sentido, entendemos que tratar de qualidade na Educação de Jovens e Adultos contempla elevar as condições dos estudantes com maiores fragilidades educacionais, contribuindo, assim, para a redução das desigualdades sociais.

O estudo apresenta alguns desafios e tensões desde o processo de implementação do PROEJA na Rede Federal, ressaltando a preocupação com a garantia da histórica "qualidade" do ensino nessas instituições com a chegada do público da EJA, os seus impactos na prática docente e no processo de ensino-aprendizagem. $\mathrm{O}$ artigo segue abordando algumas considerações sobre a formação docente no PROEJA, apontando possíveis dificuldades e obstáculos enfrentados na construção de uma prática educativa emancipatória.

\section{Desafios e tensões do PROEJA na rede federal: a qualidade em questão}

Os cursos do PROEJA eram ofertados, principalmente, pelas instituições federais, reconhecidas tradicionalmente pela qualidade do ensino, "ou seja, o lugar de excelência de formação profissional do país agora teria o desafio de manter essa excelência com um público diferenciado do que vinha atendendo" (MACHADO, 2011, p.20).

O processo de implementação do PROEJA na rede federal foi marcado, por um lado, pela expectativa do êxito devido ao alto nível de titulação dos docentes desta rede e pelo histórico de excelência nos cursos técnicos ofertados pelas instituições federais. Contraditoriamente, também foi marcado pela forte preocupação com a possível queda da qualidade do ensino nessas instituições, com a entrada de sujeitos procedentes das parcelas mais pobres da população que constituem o público da EJA. Esta, entre outras questões, compreende a ideia de que os jovens e adultos das camadas populares não teriam condições de manter o nível de qualidade historicamente atribuído a essas instituições.

Assim, pode-se considerar que, no caso do PROEJA, ofertado em instituições consagradas tradicionalmente pela sua "qualidade", ao contemplar os jovens e adultos das camadas 
populares:

[...] produziu-se um novo modelo de escola, formulando novos problemas, novas possibilidades, exigindo novas elaborações teóricas e práticas, gerando um amplo processo de indagação e redefinição do papel da escola na sociedade e, simultaneamente, das próprias práticas pedagógicas (ESTEBAN, 2013, p.24).

Paiva (2013) ressalta que o conceito de qualidade "garantia a possibilidade de acesso a poucos, na condição de educação como privilégio, o que mantinha as massas populares afastadas da escolarização e assegurava, consequentemente, sucesso pelo fato de o privilégio ficar restrito aos filhos da elite econômica". (PAIVA, 2013, p.88). Sendo assim, é possível afirmar que, no caso das Instituições Federais de Educação Profissional e Tecnológica, que antes não atendiam os estudantes das camadas populares "o desafio está em ampliar a oferta da educação técnica de nível médio, incorporando o público da EJA e mantendo a histórica qualidade de sua formação" (MOLL, 2010, p.136).

Contudo, para manter a excelência na totalidade de cursos oferecidos, entre eles, o PROEJA, são vários os desafios que se colocam. É fundamental, portanto, não perder de vista que "qualidade é um conceito histórico, que se altera no tempo e no espaço, vinculando-se às demandas e exigências sociais de um dado processo" (BRASIL, 2010, p.46). Nesse contexto, é importante considerar que é também um conceito em disputa na sociedade, que abrange distintas concepções. Assim, pode-se afirmar que:

Qualidade, como conceito cujo valor é socialmente construído, e intrinsecamente ligado à concepção de sociedade e, consequentemente, de educação, inclui, na tentativa de definição, um modo de produzir um mundo, o que pode desencadear falsos consensos. Os diversos interesses em disputa e múltiplas maneiras de pensá-los, ideologizadamente, possibilitam a transformação do discurso da qualidade em discurso híbrido, em que posições divergentes convivem como se fossem da mesma ordem, mesmo quando se pretende atualizar esse conceito. Convivem, em um mesmo espaço, diferentes concepções de qualidade, porque a existência de uma nova concepção não necessariamente substitui a anterior [...] (PAIVA, 2013, p.87).

É importante analisar se o discurso sobre a qualidade corrobora com a perspectiva de uma escola seletiva, indo na contramão da proposta de uma educação para todos, visto que "há 
uma tensão permanente, marcada por interesses diversos, de modo que o discurso da busca de qualidade pode estar ocultando uma prática cujo objetivo é aprofundar as distâncias sociais, econômicas e culturais entre os indivíduos" (ESTEBAN, 2013, p.28).

Segundo Paiva (2013) ainda que a legislação brasileira defina que a educação pública deve ser de qualidade, não há parâmetros que definam qualidade para a educação brasileira. A autora destaca a polissemia do conceito, que pode trazer múltiplos significados. Nesse sentido:

A polissemia do conceito garante à qualidade sentidos e significados diversos, segundo tempos históricos e concepções, o que possibilita afirmar a relação sincrônica que este estabelece com tempo e lugar; com projeto popular e hegemônico, dependendo de quem o faz, para quem o faz, para que ofaz, em disputa permanente, o que implica explicitação das concepções que se forjaram, ao servirem aos diversos "senhores" da educação no país [...] (PAIVA, 2013, p.85)

Contudo, Paiva (2013) considera algumas dimensões integrantes do conceito de qualidade, entre elas: "insumos financeiros e infraestruturais; gestão; o projeto educacional e processos de ensino e aprendizagem; avaliação; demanda e fluxo escolar; trajetória escolar; formação continuada, relações no espaço escolar [...]" (PAIVA, 2013, p.90).

Em concordância com esses aspectos, pode-se considerar que, no caso do PROEJA, existiam fragilidades referentes às especificidades da EJA, principalmente pelo fato de grande parte dos profissionais da rede federal não possuir formação específica e nem experiência de atuação na modalidade, o que traz implicações nas relações entre docentes e estudantes e impactos sobre o processo de ensino e aprendizagem, gerando um distanciamento de algumas dimensões consideradas integrantes do conceito de qualidade.

\section{A formação docente no PROEJA: caminhos e descaminhos na construção de uma prática educativa emancipatória}

No que tange à formação docente, apesar da proposição de alguns cursos de formação continuada para os docentes do PROEJA, as iniciativas apresentavam conflitos em relação ao perfil dos professores da rede federal, possuidores de títulos de mestrado e doutorado. Além disso, com a ausência de formação inicial sobre fundamentos da EJA, muitas vezes, a falta de 
conhecimento sobre a proposta e as concepções da modalidade podem reforçar a perspectiva do ensino compensatório, afetando sua relação com os estudantes e com o conhecimento. Tal realidade também está relacionada ao fato de muitas universidades brasileiras não contemplarem de forma significativa a Educação de Jovens e Adultos em seus cursos de licenciatura, enfatizando o ensino médio propedêutico.

Desta forma, pode-se considerar que a preocupação com a manutenção do nível da qualidade da instituição e o fato de grande parte dos docentes da rede federal não possuírem formação específica em EJA se refletem, muitas vezes, em práticas e metodologias dissociadas da realidade dos sujeitos da EJA, e, consequentemente, na produção de resultados escolares que não dialogam e nem representam efetivamente a real dimensão dos conhecimentos e experiências trazidos por esses jovens e adultos, quando, na realidade, a educação deve ser reconhecida como prática social que permite a construção de conhecimentos e emancipação dos sujeitos. Nesse sentido:

[...] a EJA abre possibilidades de superação de modelos curriculares tradicionais, disciplinares e rígidos, possibilitando a desconstrução e construção de modelos curriculares e metodológicos, observando as necessidades de contextualização frente à realidade do educando, promovem a ressignificação de seu cotidiano. Essa concepção permite a valorização dos saberes oriundos de outros processos, construídos e adquiridos fora dos espaços educacionais formais (BRASIL, 2006, p.48).

O PROEJA exige transformações nas práticas pedagógicas, visto que sua proposta não permite meras adaptações do ensino regular. Embora o Documento Base do PROEJA (2007) deixe clara a possibilidade de atuação docente nos vários níveis de ensino e cursos da instituição, também enfatiza a necessidade de assumir a EJA como um campo específico, considerando que a prática escolar cotidiana deve ser constantemente repensada a partir dos diferentes contextos. Assim, é importante destacar que:

Outro aspecto irrenunciável é o de assumir a EJA como um campo de conhecimento específico, o que implica investigar, entre outros aspectos, as reais necessidades de aprendizagem dos sujeitos alunos; como produzem/produziram os conhecimentos que portam, suas lógicas, estratégias e táticas de resolver situações e enfrentar desafios; como articular os conhecimentos prévios produzidos no seu estar no mundo àqueles 
disseminados pela cultura escolar; como interagir, como sujeitos de conhecimento, com os sujeitos professores, nessa relação de múltiplos aprendizados; de investigar, também, o papel do sujeito professor de EJA, suas práticas pedagógicas, seus modos próprios de reinventar a didática cotidiana, desafiando-o a novas buscas e conquistas - todos esses temas de fundamental importância na organização do trabalho pedagógico (BRASIL, 2007, p.135).

Desta forma, a questão da formação docente no PROEJA ainda representa um grande desafio que perpassa a construção de estratégias que, de fato, viabilizem a formação continuada desses profissionais, tendo em vista que o trabalho docente deve responder as reais necessidades desses jovens, adultos e idosos, no sentido de assegurar sua permanência na escola.

Além da necessidade de compreensão da EJA e suas especificidades, ainda se faz relevante o entendimento do PROEJA enquanto uma política que integra três campos distintos: o ensino médio, a educação profissional e a educação de jovens e adultos. E, nesse sentido, a ausência de formação específica em EJA pode dificultar ainda mais a realização do diálogo entre essas três áreas, trazendo limitações ao processo educativo. Assim, pode-se considerar que o trabalho com o currículo integrado é também um dos grandes desafios enfrentados pelos docentes no PROEJA, no qual:

Os fundamentos político-pedagógicos que norteiam a organização curricular para o cumprimento dessa política são: a integração curricular visando à qualificação social e profissional articulada à elevação da escolaridade, construída a partir de um processo democrático e participativo de discussão coletiva; a escola formadora de sujeitos articulada a um projeto coletivo de emancipação humana; a valorização dos diferentes saberes no processo educativo; a compreensão e consideração dos tempos e espaços de formação dos sujeitos da aprendizagem; a escola vinculada à realidade dos sujeitos [...] (BRASIL, 2007, p.47).

O Documento Base do PROEJA (2007) prevê que a organização curricular deve ser uma construção contínua, processual e coletiva que envolve todos os sujeitos que participam do Programa, ou seja: alunos, gestores e docentes. Nesse sentido, essa construção deve se basear no diálogo com a realidade do público da modalidade EJA. Por meio de uma organização curricular que respeita as especificidades da modalidade e seus sujeitos: 
[...] considera-se que a EJA abre possibilidades de superação de modelos curriculares tradicionais, disciplinares e rígidos. A desconstrução e construção de modelos curriculares e metodológicos, observando as necessidades de contextualização frente à realidade do educando, promovem a ressignificação de seu cotidiano. Essa concepção permite a abordagem de conteúdos e práticas inter e transdisciplinares, a utilização de metodologias dinâmicas, promovendo a valorização dos saberes adquiridos em espaços de educação não-formal, além do respeito à diversidade (BRASIL, 2007, p.48).

De modo geral, os sujeitos do PROEJA tem como característica a diversidade, sendo as turmas heterogêneas, constituídas de jovens, adultos e idosos, que, de modo geral, ficaram muito tempo afastados da escola e que apresentam objetivos distintos em relação ao retorno aos estudos. Trata-se de um público diferenciado, e que, portanto, demanda a formação de professores que compreendam suas especificidades. Assim:

Jovens e adultos chegam a estes cursos motivados por interesses distintos, evadiram da escola por diferentes razões, mas desejam dar continuidade aos estudos e se qualificar para terem mais chances mercado de trabalho ou acessarem o ensino superior. A composição heterogênea do alunado demanda redobrado empenho dos professores para construírem metodologias, recursos didáticos apropriados e formas inovadoras de ensinar e avaliar para que não reforcem, também no espaço da EJA, as experiências vividas pelos alunos de múltiplas exclusões (SHIROMA; LIMA FILHO, 2011, p.732).

As inúmeras defasagens escolares trazidas pelos alunos, seja por um ensino fundamental precário, seja pelo longo distanciamento da escola, justificam, muitas vezes, o insucesso do curso, como se esse perfil de alunado inviabilizasse o êxito da formação pretendida. Entretanto, além do problema da baixa qualidade do ensino, está a segmentação socioeconômica das escolas que têm destinado a poucos uma educação de qualidade, gerando, muitas vezes, um descompasso entre o grau de ensino e o nível real de conhecimentos dos alunos.

Desta forma, atuar com o público da EJA traz desafios reais, como a necessidade de rever e flexibilizar conteúdos, processos avaliativos, metodologias de ensino, realizar diagnóstico do perfil dos alunos, entre outros. Todavia, isso não significa abrir mão da qualidade, e sim, reconhecer que o aprendizado só ocorre se os conhecimentos fizerem sentido e estiverem relacionados às realidades dos sujeitos. Implica ainda reconhecer que o trabalho docente é constituído da necessidade constante de repensar a prática. 
Nesse sentido, a sociedade contemporânea precisa cada vez mais de docentes que tenham compromisso social com uma educação emancipatória e que se disponham a repensar os processos avaliativos, bem como metodologias de ensino que priorizam, muitas vezes, o cumprimento do programa de conteúdos, sem a real preocupação com o aprendizado, visto que, por meio desta lógica, pode-se considerar que a avaliação tem servido para dizer "quem tem ou não condição de estar onde está" (SANTOS; MARTINS; BARACHO, 2010, p.222), quando na realidade "entende-se que avaliar é reconhecer criticamente a razão da situação em que se encontra o aluno e os obstáculos que o impedem de ser mais" (BRASIL, 2007, p.35), tendo em vista romper com o histórico de exclusões e desigualdades de oportunidades educacionais por ele vivenciadas. Nesse contexto:

O que importa é que não se reproduzam, pela avaliação, as exclusões vigentes no sistema, que reforçam fracassos já vivenciados e corroboram a crença internalizada de que não são capazes de aprender, substituindo esse modelo pela ratificação da autoestima que qualquer processo bem-sucedido pode produzir, reafirmando a disposição da política de cumprir o dever da oferta da educação com qualidade, devida a tantos brasileiros pelo Estado (BRASIL, 2007, $55)$.

Assim, é relevante ressaltar que ao adotar uma concepção de avaliação que reforça incapacidades e fracassos, "a desigualdade social passa a ser concebida como realidade inescapável, isto é, como dado inquestionável; portanto, a inferioridade passa a ser naturalizada até mesmo pelos sujeitos que a vivenciam"(GIOVANETTE, 2011, p.245). Em concordância com esse aspecto:

[...] ao se analisar a Educação de Jovens e Adultos em um sentido amplo, tomando-se como referência a pluralidade dos sujeitos que dela fazem parte, constata-se que, longe de estar servindo à democratização das oportunidades educacionais, ela se conforma no lugar dos que podem menos e também obtêm menos (ANDRADE, 2004, p.1).

Nesse contexto, tendo em vista a superação dessa realidade, a prática docente se torna aspecto fundamental de luta, resistência e transformação da realidade social excludente vivida por muitos jovens, adultos e idosos no país. No caso do PROEJA, "a concepção de avaliação defendida para essa política exige que aconteça de forma contínua e sistemática, mediante 
interpretações qualitativas dos conhecimentos produzidos e reorganizados pelos alunos" (BRASIL, 2007, p.53). Assim, é necessário que as propostas curriculares dos programas destinados a esses sujeitos tenham como foco suas reais necessidades e interesses, bem como se proponham a valorizar os saberes trazidos por esses educandos.

A existência de práticas descontextualizadas, que desconsideram as especificidades da EJA e de seus sujeitos, e que ao invés de serem pensadas com base nos sujeitos concretos da EJA, ainda têm como referência um tipo de aluno idealizado, gera, muitas vezes, um distanciamento entre ensino e aprendizagem. Tal situação pode estar relacionada ao fato de que:

A maioria dos cursos de formação de professores nos prepara para atuar com o aluno ideal e - por que não dizer? - irreal. Aprendemos os conteúdos de nossas áreas, conhecemos algumas ferramentas pedagógicas e metodológicas, mas estamos longe de pensar a realidade concreta da escola na qual iremos atuar. (MACHADO, 2009, p.30).

Tal quadro acaba por gerar novas exclusões, num cenário de aparente inclusão, visto que contribui para a evasão, que, historicamente, é considerada um dos maiores desafios na EJA. Em concordância com esse aspecto, o Documento Base do PROEJA (2009) afirma que "os fundamentos das práticas pedagógicas permanecem reproduzindo modelos culturais de classes sociais diversas das dos alunos, produzindo o fracasso escolar e a chamada evasão". (BRASIL, 2009, p.18).

Por outro lado, as "carências" dos alunos do PROEJA são apontadas como fatores que dificultam uma inclusão escolar bem sucedida desses sujeitos, culpabilizando-os, de certa forma, pelo fracasso escolar. Contudo, ainda que apresentem "lacunas" em seu processo de escolarização:

É oportuno e necessário dizer que a EJA, a EPT e o PROEJA não devem ser vistos como serviços de atendimento a carentes: são direitos, direitos à educação básica à educação profissional. Porém, na perspectiva fragmentadora e de subordinação, os alunos populares são vistos pela carência [...] (SHIROMA; LIMA FILHO, 2011, p.738).

A visão de baixo valor social dos alunos e as poucas expectativas em relação ao êxito na 
escolarização e ao futuro profissional, também contribuem para a naturalização do discurso pelo qual os alunos da EJA estão sempre fadados a uma trajetória marcada pelo fracasso escolar.

Nesse sentido, um dos grandes desafios que se colocam à EJA é a necessidade de políticas como o PROEJA contemplarem esses jovens e adultos enquanto sujeitos de direitos, inclusive do direito à educação, o que perpassa o entendimento da importância de valorizar os saberes cotidianos trazidos pelos sujeitos, quase sempre ignorados pela instituição escolar.

O reconhecimento desse direito perpassa a questão da permanência e é fundamental para proporcionar um processo educativo marcado por uma inclusão efetiva das camadas populares.

\section{Considerações finais}

Embora hoje tenham se ampliado o número de políticas e programas que viabilizam o acesso de jovens, adultos e idosos à educação básica, entre eles o PROEJA, essas ações não representam a garantia do direito à educação, quando suas práticas não dialogam com os saberes, as experiências e realidades dos sujeitos. Na contramão de garantir a permanência e o êxito, ao reproduzir práticas descontextualizadas, a escola reafirma que eles não são dignos do acesso ao conhecimento sistematizado.

Nesse sentido, se faz necessário o desenvolvimento de ações que efetivamente contemplem as reais necessidades, especificidades e expectativas desses jovens, adultos e idosos, que se desvinculem da perspectiva compensatória que persegue a trajetória da EJA e que se baseiem na perspectiva do direito.

A entrada de jovens, adultos e idosos das camadas populares nas instituições da rede federal de ensino por meio do PROEJA, vem ressignificando a função social dessas escolas, provocando, inclusive, a reflexão do que seria qualidade nessa rede diante desse novo contexto. Sendo assim, pode-se considerar que a EJA integrada à educação profissional, materializada no PROEJA, representa uma importante conquista para esses sujeitos.

Contudo, foi possível constatar que há entraves na percepção de qualidade relacionada às práticas docentes, concepções curriculares e ao ensino, que têm impacto na permanência de jovens, adultos e idosos no Programa. Constatou-se ainda que a preocupação com o discurso da 
qualidade e a falta de formação docente em EJA se refletem, muitas vezes, em práticas e metodologias dissociadas da realidade dos sujeitos, gerando resultados escolares que não representam a real dimensão dos conhecimentos trazidos por eles.

Desta forma, entender a EJA como um direito e ressignificar seus processos de aprendizagem também perpassa compreender o contexto em que esses jovens e adultos estão inseridos, e que o conceito de qualidade está, na realidade, relacionado ao pressuposto de elevar as condições dos estudantes que apresentam maiores fragilidades no sentido de proporcionarIhes maiores e reais possibilidades de humanização.

Com base nessa perspectiva e considerando que ainda existem muitos desafios a serem enfrentados no PROEJA para a garantia de um processo educativo emancipatório, a docência no Programa assume um papel relevante, já que o PROEJA se propõe a integrar níveis e modalidades de ensino que historicamente têm dificuldades para dialogar, como é o caso da educação básica (ensino fundamental ou ensino médio), a EJA e a educação profissional. Nesse sentido, é necessária a continuidade de estudos a respeito das práticas pedagógicas e da formação docente no PROEJA, tendo em vista assegurar propostas que fortaleçam a atividade docente, visando transformar a realidade social excludente vivenciada pelos sujeitos que são o público alvo do PROEJA.

\section{Referências}

ANDRADE, E. R. A educação de jovens e adultos e os jovens do "último turno": produzindo outsiders. 2004. 220f. Tese (Doutorado em Educação) - Faculdade de Educação da Universidade Federal Fluminense, Niterói, 2004.

BRASIL. Decreto 2.208, de 17 de abril de 1997. Regulamenta o § 2으 do art.36 e os arts. 39 a 42 da Lei no 9.394, de 20 de dezembro de 1996, que estabelece as diretrizes e bases da educação nacional. Disponível em: http://www.planalto.gov.br/ccivil_03/decreto/D2208.htm. Acesso em: 22 jan.2020.

BRASIL. Decreto no 5.154 de 23 de julho de 2004. Regulamenta o § 2ㅇ do art. 36 e os arts. 39 a 41 da Lei no 9.394, de 20 de dezembro de 1996, que estabelece as diretrizes e bases da educação nacional, e dá outras providências. Disponível em: http://www.planalto.gov.br/ccivil_03/_Ato2004-2006/2004/Decreto/D5154.htm. Acesso em: 22 jan.2020. 
BRASIL. Decreto no 5.478 de 24 junho de 2005. Institui, no âmbito das instituições federais de educação tecnológica, o Programa de Integração da Educação Profissional ao Ensino Médio na Modalidade de Educação de Jovens e Adultos - PROEJA. Disponível em: http://www.planalto.gov.br/ccivil_03/_ato2004-2006/2005/Decreto/D5.478.htm. Acesso em 22 jan 2020.

BRASIL. Decreto no 5.840 de 13 de julho de 2006. Institui, no âmbito federal, o Programa Nacional de Integração da Educação Profissional com a Educação Básica na Modalidade de Educação de Jovens e Adultos - PROEJA, e dá outras providências. Disponível em: http://www.planalto.gov.br/ccivil_03/_ato2004-2006/2006/decreto/D5840.htm. Acesso em 22 jan 2020.

BRASIL. Ministério da Educação. Secretaria de Educação Profissional e Tecnológica. Documento base. Programa de Integração da Educação Profissional Técnica de Nível Médio na Modalidade de Educação de Jovens e Adultos - PROEJA. Brasília: 2006.

BRASIL. Ministério da Educação. Secretaria de Educação Profissional e Tecnológica. Documento base. Programa Nacional de Integração da Educação Profissional com a Educação Básica na Modalidade de Educação de Jovens e Adultos - PROEJA. Educação Profissional Técnica de Nível Médio / Ensino Médio. Brasília: 2007.

BRASIL. Ministério da Educação. Secretaria de Educação Profissional e Tecnológica. Documento base. PROEJA - Programa Nacional de Integração da Educação Profissional com a Educação Básica na Modalidade de Educação de Jovens e Adultos. Educação Profissional Técnica de Nível Médio / Ensino Médio. Brasília: 2009.

BRASIL. Ministério da Educação. Documento final CONAE 2010: construindo o Sistema Nacional Articulado de Educação. Brasília, MEC, 2010.

ESTEBAN, M. T. O que sabe quem erra? Petrópolis: De Petrus et Alii, 2013.

GIOVANETTI, M. A. G. C. A formação de educadores de EJA: o legado da educação popular. In: SOARES, L.; GIOVANETTE, M. A. G. C.; GOMES, N. L. (orgs.). Diálogos na educação de jovens e adultos. Belo Horizonte: Autêntica, 2011. p.243-254.

MACHADO, M. M. A educação de jovens e adultos no Brasil pós-Lei 9.394/96: a possibilidade de constituir-se como política pública. Em Aberto, Brasília, v.22, n.82, p.17-39, nov. 2009.

MACHADO, M. M. A pesquisa como foco na educação de trabalhadores a partir do PROEJA. In: MACHADO, M. M.; RODRIGUES, M. E. C. Educação dos trabalhadores: projetos e políticas em disputa. Campinas: Mercado de Letras, 2011, p.19-34.

MOLL, J. PROEJA e democratização da educação básica: educação profissional e tecnológica no Brasil contemporâneo: desafios tensões e possibilidades. Porto Alegre: Artmed, 2010. 
PAIVA. J. Qualidade na educação de jovens e adultos: traduções em disputa na prática de redes públicas no Rio de Janeiro. Cadernos de Pesquisa em Educação, Vitória. Ano 10, v.19, n.37, p.79-108, jan./jun.2013. Disponível em: https://pdfs.semanticscholar.org/365f/25a1edef806b58ef27290292888929aa0090.pdf. Acesso em: 22 jan.2020.

VENTURA, J. A trajetória histórica da educação de jovens e adultos trabalhadores. In: TIRIBA, L.; CIAVATTA, M. (orgs.). Trabalho e educação de jovens e adultos. Brasília: Liber Livro e Editora UFF, 2011, p.57-93.

SANTOS, B. A.; MARTINS, F. I. B. B.; BARACHO, M. G. Diálogos PROEJA: uma experiência no Instituto Federal de Educação, Ciência e Tecnologia do Rio Grande do Norte. In: MOURA, D. H.; BARACHO, M. G. PROEJA no IFRN: práticas pedagógicas e formação docente. Natal: IFRN Editora, 2010, p.213-230.

SHIROMA, E. O.; LIMA FILHO, D. L. Trabalho docente na educação profissional tecnológica e no PROEJA. Revista Educação e Sociedade. Campinas, v.32, p.725-743, 2011. Disponível em: www.cedes.unicamp.br Acesso em: 17 jan.2020.

Recebido em fevereiro 2020.

Aprovado em agosto 2020. 